\title{
Strong morphological defects in conditional Arabidopsis abp1 knock-down mutants generated in absence of functional
}

\section{ABP1 protein [version 1; peer review: 1 approved, 2 approved with reservations]}

\author{
Jaroslav Michalko ${ }^{1,2^{*}}$, Matouš Glanc ${ }^{1,3^{*}}$, Catherine Perrot-Rechenmann4 ${ }^{4}$ Jiří Friml ${ }^{1}$ \\ ${ }^{1}$ Institute of Science and Technology Austria, Klosterneuberg, Austria \\ 2Institute of Plant Genetics and Biotechnology, Slovak Academy of Sciences, Nitra, Slovakia \\ ${ }^{3}$ Department of Experimental Plant Biology, Faculty of Sciences, Charles University, Prague, Czech Republic \\ ${ }^{4}$ Institut Jean-Pierre Bourgin, INRA, AgroParisTech, CNRS, Université Paris-Saclay, Versailles, France \\ * Equal contributors
}

V1 First published: 20 Jan 2016, 5:86

https://doi.org/10.12688/f1000research.7654.1

Latest published: 20 Jan 2016, 5:86

https://doi.org/10.12688/f1000research.7654.1

\section{Open Peer Review}

\begin{tabular}{cccc} 
Approval Status & $? \checkmark$ \\
& 1 & 2 & 3 \\
\hline version 1 & $?$ & & $?$ \\
\hline 20 Jan 2016 & view & view & view
\end{tabular}

1. Lars Ostergaard, John Innes Centre, Norwich, UK

2. Richard M. Napier, University of Warwick, Coventry, UK

\section{Christian Luschnig, University of Natural}

Resources and Life Sciences, Vienna, Austria Any reports and responses or comments on the article can be found at the end of the article.

Arabidopsis, auxin , AUXIN BINDING PROTEIN 1 (ABP1), knock-down mutant, off-target 
Corresponding author: Jiř́ Friml (jiri.friml@ist.ac.at)

Competing interests: No competing interests were disclosed.

Grant information: This work was supported by ERC Independent Research grant (ERC-2011-StG-20101109-PSDP to JF). JM internship was supported by the grant "Action Austria - Slovakia". MG was supported by the scholarship "Stipendien der Stipendienstiftung der Republik Österreich". Work by EH and CPR were supported by ANR blanc ANR-14-CE11-0018.

Copyright: @ 2016 Michalko J et al. This is an open access article distributed under the terms of the Creative Commons Attribution License, which permits unrestricted use, distribution, and reproduction in any medium, provided the original work is properly cited. Data associated with the article are available under the terms of the Creative Commons Zero "No rights reserved" data waiver (CC0 1.0 Public domain dedication).

How to cite this article: Michalko J, Glanc M, Perrot-Rechenmann C and Friml J. Strong morphological defects in conditional Arabidopsis abp1 knock-down mutants generated in absence of functional ABP1 protein [version 1; peer review: 1 approved, 2 approved with reservations] F1000Research 2016, 5:86 https://doi.org/10.12688/f1000research.7654.1

First published: 20 Jan 2016, 5:86 https://doi.org/10.12688/f1000research.7654.1 


\section{Introduction}

The naturally occurring auxin, indole-3-acetic acid, plays a central role in plant growth and development alone or in orchestration with other plant hormones. Proper sensing and interpretation of fluctuating cellular auxin signals is necessary for mediating a diverse range of developmental and cell biology responses (Enders \& Strader, 2015; Grunewald \& Friml, 2010; Paciorek et al., 2005; Petrasek et al., 2006). In the early screens for auxin receptors, Auxin Binding Protein 1 (ABP1) has been identified based on its ability to bind auxin with high affinity (Hertel et al., 1972; Löbler \& Klämbt, 1985) and soon became a prime candidate for an extracellular auxin receptor based mainly on electrophysiological studies utilizing antibodies against ABP1 that showed rapid ABP1-mediated modulation of plasma membrane ion transport in an early step of auxin action (Barbier-Brygoo et al., 1989; Leblanc et al., 1999). Over the next decades, the auxin-binding activity of ABP1 has been characterized in detail by biochemical studies (Batt et al., 1976; Napier et al., 2002; Napier \& Venis, 1995; Ray et al., 1977) and its protein structure including the auxin-binding pocket has been revealed (Woo et al., 2002). Phylogenetic studies have shown that ABP1 homologues are present in the genomes of all plant species from bryophytes to flowering plants (Tromas et al., 2010) with more than one copy present e.g. in the genome of maize, rice, poplar or the moss Physcomitrella patens (http://phytozome.jgi.doe.gov/pz/portal.html).

Since its discovery, however, the biological importance of the ABP1 protein as a plasma membrane auxin receptor has been a matter of debates, in part because of its predominant subcellular localization in the endoplasmic reticulum (ER) in maize where the conditions for auxin binding are unfavorable (Habets \& Offringa, 2015; Napier et al., 2002). Recently, these discussions were revived by the isolation of two new Arabidopsis abpl knock-out alleles, abplcl and abpl-TD1 (Gao et al., 2015) that show no obvious phenotypes under standard growth conditions. The contradiction between this observation and the previously published embryo-lethal phenotypes of abpl mutants (Chen et al., 2001; Tzafrir et al., 2004) has recently been clarified by proving that the embryo-lethality of the originally reported alleles $a b p 1-1$ and $a b p l-1 s$ was caused by disruption of the tightly-linked neighboring gene BELAYA SMERT (BSM) rather than knock-out of $A B P 1$ (Dai et al., 2015; Michalko et al., 2015). This correction and the demonstration of normal embryo development in the abpl knock-outs (Michalko et al., 2015) suggest that ABP1 plays no essential role in early Arabidopsis embryogenesis.

The ongoing discussion focuses on the relevance of $A B P 1$ in auxin signaling and other post-embryonic auxin-related biological processes that have been demonstrated using different genetic tools, namely the conditional knock-down (KD) lines, the abpl-5 weak allele harboring a point mutation in the ABP1 auxin-binding pocket and gain-of-function alleles, all of which often provided internally consistent results (Braun et al., 2008; Čovanová et al., 2013; David et al., 2007; Grones et al., 2015; Robert et al., 2010; Sassi et al., 2014; Tromas et al., 2013; Xu et al., 2010; Xu et al., 2014).

Conditional ABP1 KD lines SS12S6, SS12K9 and abp1-AS have been generated using two fundamentally different approaches of gene or protein down-regulation. In the SS12S6 and SS12K9 lines, $\mathrm{ABP} 1$ was inactivated by inducible over-expression of a recombinant immunoglobulin fragment termed single-chain fragment variable (scFv) (Conrad \& Fiedler, 1998). This construct, consisting of the heavy- and light-chain variable domains of a wellcharacterized anti-ABP1 monoclonal antibody mAb12 (David \& Perrot-Rechenmann, 2001; David et al., 2007; Leblanc et al., 1999) linked by a flexible peptide was additionally fused to

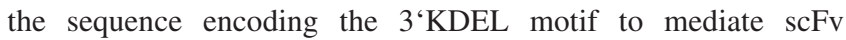
ER-retention in the SS12K9 line, while the SS12S-encoded scFv12 was meant to be secreted to the apoplast. In planta-produced scFv12 was able to pull down ABP1, and reciprocally immunoprecipitation of ABP1 using another antibody was shown to pull down scFv12 (Tromas et al., 2009). An antisense approach was utilized in the abpl-AS line, where inducible over-expression of full-length $A B P 1$ antisense cDNA led to the formation of duplexes with its sense mRNA, thus preventing ABP1 translation, and potentially also transcription by RNA interference mechanism (Meister \& Tuschl, 2004; Tufarelli et al., 2003). Both antibodyand antisense-based lines use the ethanol-inducible system, which is well established and widely used for the conditional expression of plant genes (Deveaux et al., 2003; Roslan et al., 2001).

These three abpl knock-down lines have been instrumental to connect ABP1 function to multiple cellular and developmental processes. For example, they showed defects in shoot and root growth (Braun et al., 2008; Tromas et al., 2009), cell wall re-modeling (Paque et al., 2014) or clathrin-mediated endocytosis of PIN auxin efflux carriers (Dhonukshe et al., 2007; Robert et al., 2010). In contrast, the $a b p 1$ gain-of-function transformants promote PIN internalization both in tobacco and Arabidopsis (Grones et al., 2015; Robert et al., 2010). Contrasting effects of $A B P 1 \mathrm{KD}$ and gain-offunction lines were shown also in the case of auxin effect on the control of leaf epidermal pavement cells morphogenesis (Braun et al., 2008; Nagawa et al., 2012) on ROP GTPase activation (Xu et al., 2010) and on microtubule rearrangement (Chen et al., 2014; Xu et al., 2014). Furthermore, analysis of ABP1 variants with mutations in the auxin-binding pocket demonstrated the importance of auxin-binding to ABP1 for its gain-of-function phenotypes (Grones et al., 2015). Altogether, these studies provided an internally consistent picture showing involvement of ABP1 signaling in multiple physiological and cellular processes. These observations were further supported by the finding that loss-of-function mutants in $T M K$ receptor-like protein kinases, that were recently shown to interact with ABP1 in an auxin-inducible manner, show similar phenotypes with abpl KD mutants (Xu et al., 2014) which was consistent with the importance of the ABP1/TMK complex-mediated auxin perception in plant development. Recent identification of wild-type looking Arabidopsis abpl loss-of-function alleles by Gao et al. (2015) thus questions the interpretation of data obtained in the aforementioned studies.

Here, we address the missing phenotypes in the true $a b p 1$ null alleles in relation to the strong and consistent morphological defects observed in the conditional abpl knock-down lines. We show that the morphological phenotypes in SS12S6, SS12K9 and $a b p 1-A S$ can be generated in the absence of functional ABP1 protein and we discuss possible underlying causes of this. 


\section{Material and methods}

Plant material and growth conditions

Arabidopsis thaliana mutants used in this study were: abpl-cl, abp1-TD1 (Gao et al., 2015), abp1-AS, SS12K9, SS12S6 (Braun et al., 2008; David et al., 2007). A. thaliana Col-0 wild type seeds were obtained from The Nottingham Arabidopsis Stock Centre (NASC, http://www.arabidopsis.info). For in vitro experiments, seeds were surface-sterilized with chlorine vapor, vernalized for 2 days in the dark at $4{ }^{\circ} \mathrm{C}$ and grown on $1 / 2 \mathrm{MS} 0.8 \%$ agar medium with or without $1 \%$ w/v sucrose $(\mathrm{pH} 5.9)$ on vertical Petri dishes under long day conditions ( $16 \mathrm{~h}$ light/ $8 \mathrm{~h}$ dark) or in complete darkness at $21^{\circ} \mathrm{C}$. A sterilized microtube with $500 \mu \mathrm{l} 5 \%$ ethanol was placed at the bottom of the plate to induce expression of abpl-AS, SS12K9 and SS12S6 constructs before germination. Plates with 5-day old etiolated or 7-day old light-grown seedlings were scanned on a flatbed scanner, phenotyped by visual examination and used for DNA/RNA extraction.

\section{Genotyping mutants}

Ethanol-inducible ABP1 down-regulating lines (abpl-AS, SS12K9, $S S 12 S 6$ ) were genotyped for the presence of the alcR gene encoding the transcriptional regulator of the ethanol-inducible system using primers alcR_for and alcR_rev (Table 1). Fragments amplified from $a b p 1-c 1$ with primer pairs ABP1-U409F + ABP1-586R or ABP1$5 \mathrm{P}+\mathrm{ABP} 1-586 \mathrm{R}$ were digested with BslI, which cuts the WT fragment once and does not cut the mutant fragment; $a b p 1-T D 1$ was genotyped as described previously (Gao et al., 2015). Genomic DNA was isolated using the CTAB extraction method. GoTaq G2 polymerase (Promega) and Bio-Rad T100 Thermal Cycler were used for PCR under following conditions: initial denaturation 5 min $98^{\circ} \mathrm{C}$; $35-45$ cycles (denaturation $30 \mathrm{~s}$ at $98^{\circ} \mathrm{C}$; annealing $30 \mathrm{~s}$ at $55^{\circ} \mathrm{C}$, elongation $1 \mathrm{~min}$ at $72^{\circ} \mathrm{C}$ ); final elongation $5 \mathrm{~min}$ at $72^{\circ} \mathrm{C}$. Restriction analysis was performed by adding the restriction enzyme directly to unpurified PCR reaction. Alternatively, Phire Plant Direct PCR Kit (Thermo Scientific by Finnzymes) and QIAquick Gel Extraction Kit (QIAGEN) were used following manufacturer's instructions to genotype the SS12K9 $x$ abpl-cl line.

\section{Quantitative RT-PCR}

Total RNA from approximately twenty 8-day old seedlings frozen in liquid nitrogen was extracted using the TRIzol reagent (Invitrogen, Carlsbad, CA, USA) and purified using RNeasy Mini Kit (Qiagen) according to manufacturer's instructions. $2 \mu \mathrm{g}$ of purified total RNA were used for a reverse transcription reaction using the iScript cDNA Synthesis Kit (BioRad). qRT-PCR was performed using the LightCycler 480 SYBR Green I Master chemistry (Roche) in a LightCycler480 II thermal cycler (Ser. no. 5659, Roche) according to manufacturer's instructions. cDNA diluted 1:10 in water was used as a template to prepare $5 \mu \mathrm{L}$ reaction mixture (final volume). Primers used for the quantitative RT-PCR were designed using QuantPrime (http://www.quantprime.de). The ABPl cDNA fragment (84 bp in length) was amplified with ABP1-2E and ABP1-586R primers. Arabidopsis Tubulin beta chain 2 (TUB2, At5g62690) amplified with TUB2-F and TUB2-R primers was used as a reference gene (Dataset 1). Gene expression was calculated with the $2^{-\Delta \Delta \mathrm{CT}}$ method (Livak \& Schmittgen, 2001). Results are expressed as the average +/- standard deviation of 2 biological and three technical replicates. Sequences of primers used for genotyping and qRT-PCR analysis are listed in Table 1.
Table 1. Primer sequences used in this study

\begin{tabular}{|l|l|}
\hline ABP1-U409F & CCTCATCACACAACAAAGTCACTC \\
\hline ABP1-586R & GGAGCCAGCAACAGTCATGTG \\
\hline ABP1-5P & ATGATCGTACTTTCTGTTGGTTCC \\
\hline ABP1-2E & TTGCCAATCGTGAGGAATATTAG \\
\hline pSKTAIL-L3 & ATACGACGGATCGTAATTTGTCG \\
\hline AlcR F & AGAACAAAGAAAGCCAGGA \\
\hline AlcR R & GCGTGAGAGAAAAGATGA \\
\hline TUB2 F & TAACAACTGGGCCAAGGGACAC \\
\hline TUB2 R & ACAAACCTGGAACCCTTGGAGAC \\
\hline
\end{tabular}

\section{Results}

Dataset 1. Scans of ethanol-induced F2 seedlings of crosses (A) SS12S6 $\times$ abp1-c1, (B) SS12S6 × abp1-TD1, (C) abp1-AS $\times$ abp1-c1, (D) abp1-AS $\times$ abp1-TD1, (E) SS12K9 $\times$ abp1-c1 and (F) SS12K9 $\times$ abp1-TD1 that were used for phenotyping and genotyping (Figure 1 and Figure 2)

http://dx.doi.org/10.5256/f1000research.7654.d110722

Dataset 2. Agarose gel images from the PCR genotyping of the F2 crosses (A) SS12S6 $\times$ abp1-c1, (B) SS12S6 × abp1-TD1, (C) abp1-AS $\times$ abp1-c1, (D) abp1-AS $\times$ abp1-TD1, (E) SS12K9 $\times$ abp1-c1 and (F) SS12K9 $\times$ abp1-TD1 (Figure 3)

http://dx.doi.org/10.5256/f1000research.7654.d110723

All crosses were genotyped for the presence of the alc $R$ transcriptional regulator (first row of the gel images) which is an integral part of the ethanol-inducible cassette in abp 1 knockdown lines. The presence of point mutation in abp1-c1 crosses was genotyped by restriction analysis of $A B P 1 \mathrm{PCR}$ product as described in Gao et al. (2015) (second row of the gel images of $a b p 1-c 1$ crosses). The presence of the T-DNA insertion in abp1TD1 crosses was genotyped according to Gao et al. (2015) (second and third row of gel images of abp1-TD1 crosses). GeneRuler DNA ladder mix \#0331 (Thermo Scientific) was used as a fragment size standard to determine the approximate size of DNA fragments. Fragment sizes of $1000 \mathrm{bp}$ and $500 \mathrm{bp}$ are indicated.

\section{Dataset 3. Source qPCR data (Figure 3c)}

http://dx.doi.org/10.5256/f1000research.7654.d110724

Individual samples are annotated with their position on a 384-well plate (column A), the cDNA (column B) and primer pair (column C); the $C p$ value of each sample is shown in column $D$. The experiment was performed in two biological (1 or 2 at the last position in column B) and three technical replicates. Figure 3c shows gene expression calculated with the $2^{-\Delta \Lambda C T}$ method (Livak \& Schmittgen, 2001) from values of $A B P 1-2 E$ and TUB as a reference gene; using $A B P 1-5 P$ and/or EF as a reference gene instead gave similar results. 


\section{A}

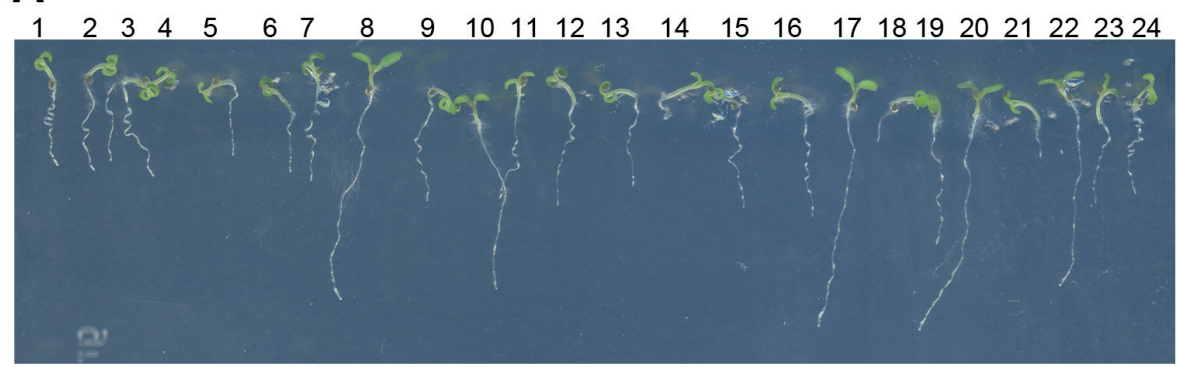

B

$\begin{array}{llllllllllllllllllllllll}1 & 2 & 3 & 4 & 5 & 6 & 7 & 8 & 9 & 10 & 11 & 12 & 13 & 14 & 15 & 16 & 17 & 18 & 19 & 20 & 21 & 22 & 23 & 24\end{array}$

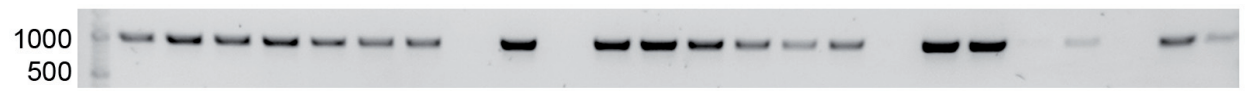

C

\begin{tabular}{|l|c|c|} 
KD phenotype & + & - \\
\hline AS x c1 & 71 & 21 \\
\hline & 130 & 47 \\
\hline $\mathbf{1 2 S 6}$ x c1 & 54 & 13 \\
\hline & 155 & 38 \\
\hline $\mathbf{1 2 K 9}$ x c1 & 41 & 28 \\
\hline & 204 & 58 \\
\hline
\end{tabular}

\begin{tabular}{|l|c|c|c|} 
KD phenotype & ++ & + & - \\
\hline AS X TD-1 & 49 & 72 & 32 \\
\hline & \multicolumn{2}{|c|}{100} & 99 \\
\hline $\mathbf{1 2 S 6} \times$ TD1 & 45 & 87 & 37 \\
\hline & \multicolumn{2}{|c|}{88} & 91 \\
\hline $\mathbf{1 2 K 9} \times$ TD1 & 22 & 43 & 13 \\
\hline & 107 & 160 \\
\hline
\end{tabular}

Figure 1. Strong morphological defects in conditional abp1 knock-down lines correlate with the presence of the ethanol-inducible cassette and segregate normally when crossed with abp1-c1 knock-out allele. (A) abp 1-AS $\times$ abp 1-c1 F2 plants grown for 7 days in the presence of $5 \%$ ethanol segregate strong morphological defects characteristic of the abp 1 conditional knock-down (KD) alleles approximately in a 3:1 ratio. (B) alcR-specific PCR bands amplified from the genomic DNA of abp 1-AS $\times$ abp1-c1 F2 plants shown in (A) demonstrate that the KD phenotype is caused by the presence of the ethanol-inducible insertion. (C) Phenotypes of the scFv12-based KD lines segregate similarly in F2 crosses with abp 1-c1, while altered segregation ratios can be observed in F2 of all three KD alleles crossed to abp 1-TD1, which is most apparent in seedlings grown for 5 days in the dark (grey background).
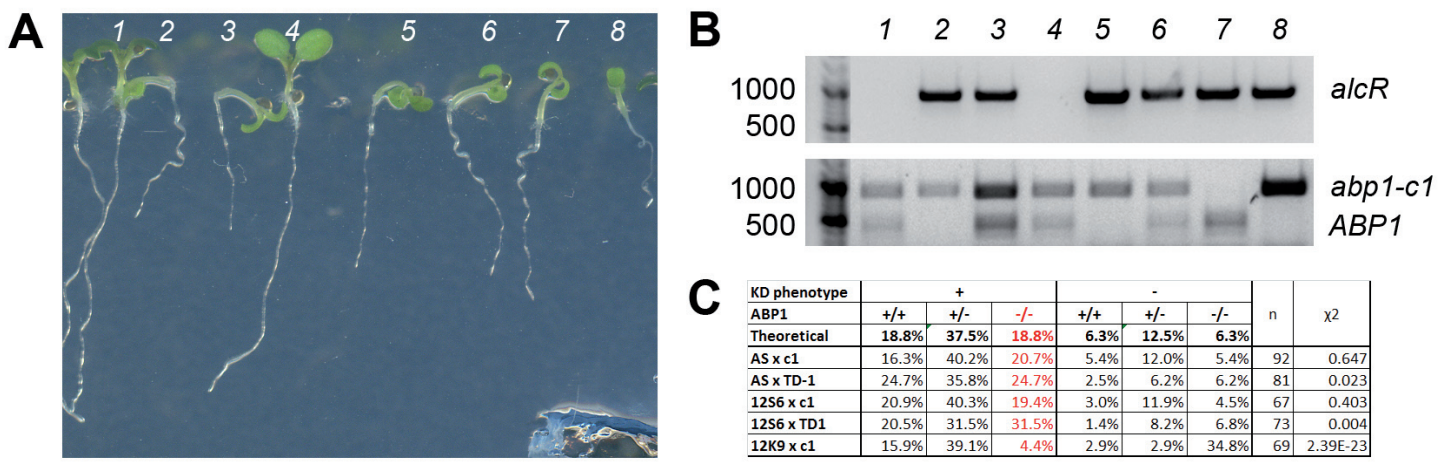

Figure 2. Mendelian segregation of strong ethanol-inducible phenotypes in the F2 generation of abp1 knock-out $\times$ knock-down crosses is independent of abp1 mutant background. (A) Representative abp1-AS $\times$ abp1-c1 F2 plants, (B) PCR products amplified from their genomic DNA and $(\mathbf{C})$ segregation ratios from all crosses show that the ethanol-inducible phenotypes segregate independently of the presence of abp 1 knock-out alleles following approximately Mendelian rules for di-hybrid crosses. Homozygous abp 1 knock-out mutants with the inducible KD phenotype could be found in all crosses (plants 2,5,8 in $(\mathbf{A})$ and $(\mathbf{B})$, red numbers in (C)), suggesting that the phenotype does not require a functional ABP1 gene. Strong deviations from the expected Mendelian segregation were detected in the SS12K9x abp 1-C1 cross, indicating genetic linkage between $A B P 1$ locus and the inserted ethanol-inducible scFv construct. 

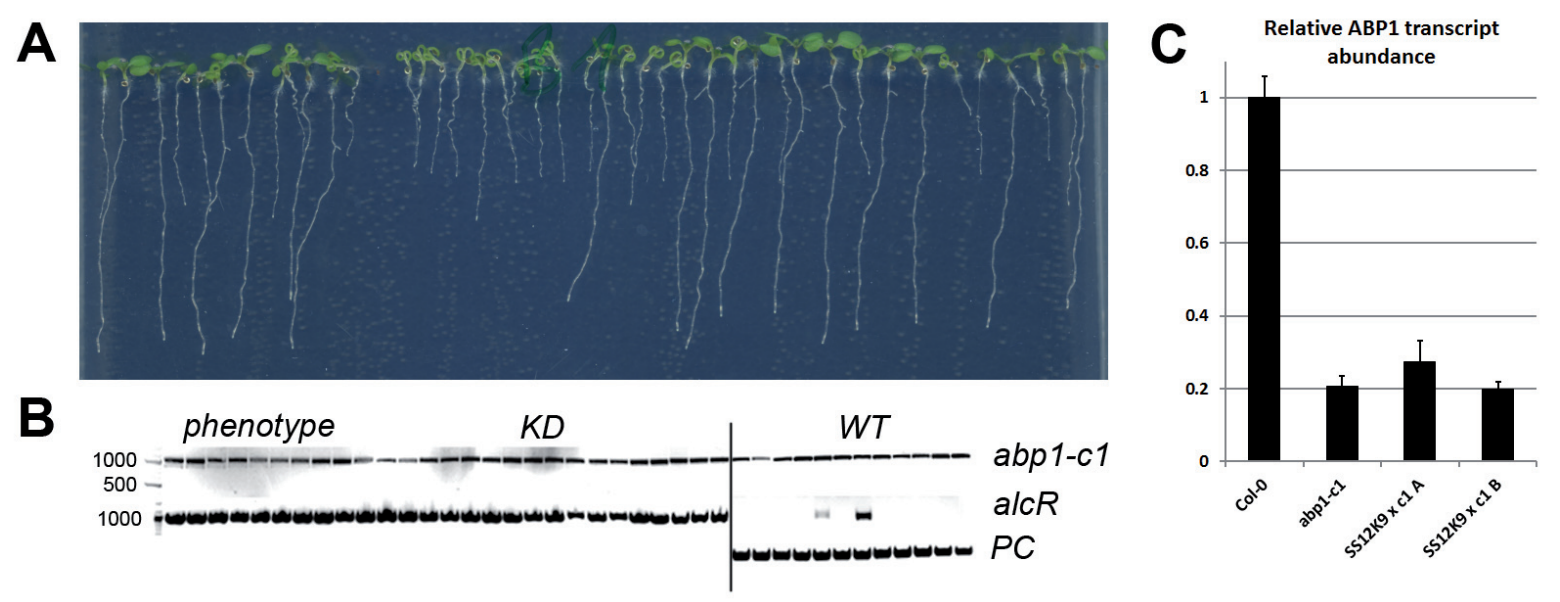

Figure 3. Strong inducible knock-down phenotypes in the absence of functional ABP1 gene confirmed in the SS12K9 $\times$ abp1-c1 F3 progeny. (A) Representative seedlings of the ethanol-induced F3 progeny of one of the SS12K $\times$ abp1-c1 F2 plants (plant A) that showed $\mathrm{KD}$ phenotype in the absence of the functional ABP1. All F3 seedlings manifesting KD phenotype were homozygous for abp 1-c1 mutation. (B) Genotyping of the plants shown in $\mathbf{A}$. The image is assemled from different regions of two gels that were copy-pasted next to each other in order to save space. (C) qRT-PCR analysis of KD-phenotype positive F3 seedlings of both lines revealed that $A B P 1$ transcript levels are reduced by about $80 \%$ like in the original abp1-c1 mutant. Altogether these data confirm that in the abp1 down-regulating lines the KD phenotype can be manifested without the ABP1 function. In (C) average of two biological and three technical replicates +/- SD is shown. PC- positive control.

\begin{abstract}
Segregation of strong morphological defects in conditional abp1 knock-down alleles crossed with abp1-TD1 and abp1-c1 knock-out alleles

To investigate the contradiction between missing phenotypic defects in the loss-of-function abpl alleles and strong morphological defects of conditional $A B P 1$ down-regulating lines (knockdown; KD), we decided to cross both types of lines to test three possible scenarios: 1) The absence of the strong morphological defects in the abpl-cl or abp1-TD1 alleles is caused by an adaptation of the plants to the permanent loss of the ABP1 function, which compensates for this deletion; 2) the strong morphological phenotypes induced in the KD lines do not require functional $\mathrm{ABP} 1$ and are caused by off-target effects; or 3) both abp 1-TD-1 and abpl-c1 lines contain background mutation(s) that suppress the phenotypes caused by the absence of ABP1.
\end{abstract}

We crossed each of the conditional lines with abpl-TD1 and abpl-c1 null mutants and with an ABP1-WTc1 line as a control and analyzed seedling phenotypes of ethanol induced F2 segregating plants (Figure 1a). We hypothesized that in case of an adaptive process, the conditional abpl KD phenotypes (short wavy roots and epinastic cotyledons) would not be manifested in homozygous abpl null background, resulting in a 9/16 KD and 7/16 WT phenotype segregation ratio. If the inducible phenotypes in the KD lines are independent of ABP1, these phenotypes will be manifested even in the absence of the functional $A B P 1$ gene, thus resulting in a classic Mendelian 3/4 KD and 1/4 WT phenotype segregation ratio. In case of the presence of background suppressive mutation(s), the KD phenotype segregation ratio would lie anywhere between 3/16 (dominant suppressor mutation closely linked to the $A B P 1$ locus) and $3 / 4$ (recessive mutation with low penetrance and no linkage to $A B P 1$ ) (Supplementary Figure 1).
Segregation of the morphological phenotypes in the F2 plants from different crosses is summarized in Figure 1b. These observations show that strong phenotypes in both the abpl antisense-based and the $\mathrm{scFv} 12$-based conditional knock-down lines segregate approximately $75 \%$ in the $\mathrm{F} 2$ crosses with abpl-cl. This observation favors the scenario that the strong morphological defects in the KD lines are not influenced by the presence or absence of the functional $A B P 1$ gene copy. The $\mathrm{F} 2$ phenotypic segregation is however shifted in favor of WT-looking plants in all three KD lines crossed to abp 1$T D 1$. This segregation shift may be ascribed to partial transcriptional silencing of the ethanol-inducible constructs due to the presence of multiple $35 \mathrm{~S}$ promoters/enhancers in the constructs themselves as well as the tandem T-DNA insertion in abp1-TD1.

We genotyped all analyzed F2 plants for the presence of the alcR transcriptional regulator, which is an integral part of the ethanolinducible system and verified that the observed morphological defects were indeed correlating with the presence of the $A B P 1$ KD constructs (Figure 1c). About 5\% of seedlings from all lines showed WT phenotype despite being positive for the presence of $a l c R$ or vice versa. As this phenomenon was independent of $A B P 1$ genetic background and could not be reproduced in F3 progeny (Supplementary Figure 2), we put it down to biological variability and/or occasional silencing of the ethanol-inducible constructs.

\section{Strong morphological defects in conditional abp 1 knock- down alleles can be manifested in homozygous abp1 knock-out alleles}

To investigate whether the $a b p l$ KD phenotypes can be observed in the absence of a functional copy of the At4g02980 ABPI gene we further genotyped the respective $a b p 1$ mutations in F2 seedlings of all crosses (Figure 2). As summarized in Figure 2c, in all crosses 
we were able to identify multiple homozygous abpl mutants that showed the strong KD phenotype following ethanol induction. This analysis demonstrates that strong morphological phenotypes in abpl antisense-based (abpl-AS) and scFv12 antibody-based (SS12S6, SS12K9) conditional KD lines can be generated also in a null $a b p 1$ background.

In case of the crosses SS12K9 $\times a b p 1-c 1$ and SS12K9 $\times a b p 1-T D 1$ we observed a lower level of allelic segregation between the $a b p 1$ mutations and the KD construct in their F2 progeny (Figure 2c). Out of 28 genotyped plants with WT phenotype, 24 (85.7\%) were homozygous for abpl mutation and did not contain the ethanolinducible KD cassette. These results point towards genetic linkage between these two loci, most likely caused by the positional effect of the KD cassette located close to the $A B P 1$ locus on the chromosome 4. Nevertheless, some level of genetic recombination was happening between the two loci in the crosses as demonstrated by the identification of three F2 SS12K9 $\times a b p 1-c 1$ plants showing KD phenotype that were homozygous for abpl-cl mutation (Figure 2c). This analysis confirms that also SS12K9 conditional KD construct can generate strong morphological phenotypes in the homozygous abpl knock-out alleles despite the insertion position being linked to the $A B P 1$ locus. Altogether these data are consistent with results obtained by the other crosses and further support that morphological phenotypes in the abpl knock-down lines can be generated in the absence of the functional ABP1.

Analysis of F3 generation confirms SS12K9-induced strong morphological defects in absence of ABP1 function

Next we tested the occurrence of the strong KD-induced morphological phenotypes in the absence of the functional ABP1 in the next generation by analyzing the F3 progeny of two $S S 12 K 9 \times$ abpl-cl plants showing strong KD phenotype. We confirmed that the F3 progeny was homozygous for the abpl-cl mutation and segregated the ethanol-inducible construct approximately in a $3: 1$ ratio (Figure $3 b$ ). After induction with ethanol, the analyzed F3 population of the $S S 12 K 9 \times a b p 1-c 1$ plant A segregated into 27 plants $(67.5 \%)$ with KD phenotype and 13 WT looking plants (32.5\%) (Figure 3). The F3 population of plant B segregated into 18 plants with $\mathrm{KD}$ phenotype $(81.2 \%)$ and $4 \mathrm{WT}$ looking plants (18.2\%) (data not shown). Genotyping of all F3 plants with ethanolinducible phenotypes revealed that they contain $\mathrm{KD}$ construct in the homozygous abpl-cl background (Figure 3b). Notably, among the 17 analyzed WT looking F3 seedlings we also identified two plants that contain the ethanol-inducible construct in homozygous $a b p l-c l$ background (Figure $3 b$ ) suggesting that in these plants the functionality of the construct was affected, most probably by its silencing. Nonetheless, the majority of the plants containing the ethanol-inducible construct generated the strong morphological phenotypes even in the $a b p 1^{-/}$homozygous background.

We also analyzed the $A B P 1$ expression in WT, $a b p 1-c 1$ and SS12K9 $\times$ abpl-c1 F3 seedlings by quantitative RT-PCR just to verify that introducing $\mathrm{KD}$ alleles does not influence, in any way, the $A B P 1$ expression (Figure 3c). We observed ca. $80 \%$ decrease in $A B P 1$ transcript levels in abpl-cl. We assume that this difference somewhat surprising, since the CRISPR-induced small deletion does not necessarily decrease transcript levels - is probably caused by the decreased stability of the mutant $m R N A$. SS $12 \mathrm{~K} 9 \times a b p 1-c 1$ F3 plants positive for the KD phenotype and homozygous for abpl-c1 showed the same $80 \%$ decrease in $A B P 1$ transcription.

In summary, the phenotypic, genotypic and expression analyses consistently showed that all three conditional abpl knock-down alleles can generate strong morphological defects also in the absence of the functional ABP1 protein.

\section{Discussion}

Strong morphological phenotypes in abp1 conditional knock-down alleles are not caused by ABP1 downregulation

All three available conditional abpl knock-down alleles have been extensively characterized and used to link number of developmental and cellular processes to the ABP1-mediated signaling (for overview, see Grones \& Friml, 2015). They are based on two unrelated strategies for down-regulation of the protein's functionality: the antisense (abpl-AS) and the scFv12 monoclonal antibody expression (SS12S6, SS12K9), which suppress the protein functionality by entirely different mechanisms and at different levels (Tromas et al., 2009). All three lines showed consistent and reproducible results in a number of different laboratories and a number of developmental, physiological and cellular processes.

Nonetheless, our analysis, made possible by the newly available abpl knock-out lines (Gao et al., 2015), strongly suggests that these observed and described effects are not caused by conditional down-regulation of the ABP1. This is supported by the fact that all three constructs show the same strong conditional phenotypes in two different homozygous abpl null alleles. This means that even in the absence of the functional ABP1 protein, the ethanol-inducible constructs are inducing phenotypic defects that were originally ascribed to the down-regulation of ABP1. Therefore, results generated using these lines need to be critically re-interpreted.

\section{Possible modes of action of abp1 conditional knock-down lines}

All three types of abpl KD Arabidopsis lines generate indistinguishable morphological phenotypes. How it is possible that independent lines using fundamentally different approaches for functional down-regulation of a unique target would have in fact the same off-target effects; we do not know. One possible explanation is that the morphological defects are an artifact of the ethanolinducible expression system. However, control lines generated in parallel using the same vector and expressing the UIDA reporter gene did not exhibit any significant growth and developmental alterations (Braun et al., 2008). Furthermore, a number of authors have used the same ethanol-inducible system to control the expression of distinct genes and to the best of our knowledge, there are no reports describing similar phenotypes by using the ethanol-inducible system for other genes in other studies (Battaglia et al., 2006; Deveaux et al., 2003; Laufs et al., 2003; Peaucelle et al., 2008; Roslan et al., 2001). This system was also used to successfully rescue mutant defects after ethanol induction of gene expression e.g. for LEAFY (Maizel \& Weigel, 2004) or for N-myristoyltransferase (Pierre et al., 2007) indicating that it is not responsible per se of the phenotypes observed with the ethanol inducible ABP1 AS 
and $\mathrm{scFv} 12$ constructs. In tobacco plants and BY-2 cells, tetracycline de-repressible promoter-driven expression of the SS12S and SS12K constructs resulted in similar growth defects as their ethanol-inducible expression in Arabidopsis (Braun et al. 2008; David et al., 2007), suggesting that the observed phenotypes are tightly correlated to the scFv12 action. The expression of the scFv12 in the cytosol had however no effect on cell proliferation in BY2 cells indicating that expression of scFv12 per se is not sufficient to generate severe phenotypes whatever its cellular localisation and that scFv12 effects are correlated to its secretion and/or retention in the ER that are known location of ABP1 (David et al., 2007).

Another possibility is that both the antisense- and antibody-based lines have off-target(s) either on the very same gene(s) or elements of a common genetic pathway. Such a hypothesis would be supported by strict similarities in the phenotypes resulting from ABP1 antisense and $\mathrm{scFv} 12$ expression and by the fact that opposite and auxin-related defects were observed in both constitutive and conditional gain-of-function Arabidopsis transgenic plants as well as transitionally expressing tobacco cells (Grones et al., 2015; Robert et al.,2010). ABP1 is placed within the superfamily of cupins based on the presence of cupin-like motifs $\mathrm{HXH}(\mathrm{X})_{11} \mathrm{G}$ and $\mathrm{P}(\mathrm{X})_{4} \mathrm{H}(\mathrm{X})_{3} \mathrm{~N}$ (where $\mathrm{X}$ is any amino-acid residue) and a $\beta$-barrel jellyroll fold subunit structure (Dunwell et al., 2004; Woo et al., 2002). The epitope recognized by the $\mathrm{scFv} 12$ might be present in proteins belonging to this functionally highly diverse protein superfamily. On the other hand, the sequence similarity of even the closest $A B P 1$ homologues in Arabidopsis does not seem to be sufficiently high to be targeted by the abpl-AS constructs, thus this explanation is unlikely as well.

We also cannot completely rule out that the WT phenotype of the abpl knock-out mutants is caused by suppressor mutation(s). However, we do not consider it very likely, as this would imply that the similar mutation(s) or mutations with similar effects are present in the genetic background of both $a b p 1-c 1$ and $a b p 1-T D 1$, which are independent alleles from independent mutant collections.

In summary, we do not understand how it is possible that the used abpl knock-down alleles generate the similar strong morphological phenotypes also in absence of the functional ABP1 protein. All possible explanations we could come up with are unlikely, including common off-targets in abpl antisense and antibody KD lines or common suppressor mutations in two different abpl knock-out alleles. Thus, more experimentation is needed to figure out what really happens in the different $a b p l \mathrm{KD}$ lines and how it is possible that they independently generate phenotypes that are so consistent.
Whatever the explanation at the end will be, in light of the presented data it seems obvious that these lines do not act solely by down-regulating the ABP1 function, despite the accumulation of well-fitting data from independent and complementary approaches. It is a sobering realization that even when you use independent approaches with all standard controls performed, there is no real guarantee that the observations will not lead you amiss.

\section{Data availability}

F1000Research: Dataset 1. Scans of ethanol-induced F2 seedlings of crosses (A) SS12S6 $\times$ abpl-cl, (B) SS12S6 $\times$ abpl-TD1, (C) $a b p 1-A S \times a b p 1-c 1$, (D) $a b p 1-A S \times a b p 1-T D 1$, (E) $S S 12 K 9 \times$ $a b p 1-c 1$ and (F) SS12K9 $\times$ abpl-TD1 that were used for phenotyping and genotyping (Figure 1 and Figure 2)., 10.5256/ f1000research.7654.d110722 (Michalko et al., 2016a).

F1000Research: Dataset 2. Agarose gel images from the PCR genotyping of the F2 crosses (A) SS12S6 $\times$ abpl-c1, (B) SS12S6 $\times$ abp1-TD1, (C) abpl-AS × abpl-c1, (D) abpl-AS × abpl-TD1, (E) $S S 12 K 9 \times a b p 1-c 1$ and (F) SS12K9 $\times a b p 1-T D 1$ (Figure 3), 10.5256/f1000research.7654.d110723 (Michalko et al., 2016b).

F1000Research: Dataset 3. Source qPCR data (Figure 3c), 10.5256/ f1000research.7654.d110724 (Michalko et al., 2016c).

\section{Author contributions}

JF, JM, CP and MG designed the experiments and wrote the manuscript, JM and MG performed most experiments and analyzed the data. All authors have seen and agreed to the final content of the manuscript.

\section{Competing interests}

No competing interests were disclosed.

\section{Grant information}

This work was supported by ERC Independent Research grant (ERC-2011-StG-20101109-PSDP to JF). JM internship was supported by the grant "Action Austria - Slovakia". MG was supported by the scholarship "Stipendien der Stipendienstiftung der Republik Österreich". Work by EH and CPR were supported by ANR blanc ANR-14-CE11-0018.

\section{Acknowledgements}

We would like to thank Mark Estelle and Yunde Zhao for providing $a b p 1-c 1, a b p 1-T D 1$ and $a b p 1-W T c 1$ seeds. We thank Emeline Huault for technical assistance. 


\section{Supplementary material}

\begin{tabular}{|c|c|c|c|}
\hline \multicolumn{4}{|c|}{ 1st scenario (adaptation) } \\
\hline SSAA & SSAa & SsAA & SsAa \\
\hline SSAa & SSaa & SsAa & Ssaa \\
\hline SSAA & SsAa & SSAA & SsAa \\
\hline SsAa & SscC & SSAa & ssaa \\
\hline
\end{tabular}

\begin{tabular}{|c|c|c|c|}
\hline \multicolumn{4}{|c|}{ 2nd scenario (off-targets) } \\
\hline SSAA & SSAa & SsAA & SsAa \\
\hline SSAa & SSaa & SsAa & Ssaa \\
\hline SSAA & SsAa & SSAA & ssAa \\
\hline SsAa & SscC & ssAa & ssaa \\
\hline
\end{tabular}

\begin{tabular}{c|c|c|c|}
\hline \multicolumn{4}{|c|}{ 3rd scenario (suppressor mutations) } \\
\hline SSAA & SSAa & SsAA & SsAa \\
\hline SSAa & SSaa & SsAa & Ssaa \\
\hline SSAA & SSAa & SSAA & SsAa \\
\hline SsAa & SscC & SSAa & ssaa \\
\hline
\end{tabular}

Supplementary Figure 1. Theoretical genotype and phenotype segregation in F2 progeny of the abp1 knock-out $\times$ knock-down cross. Expected genotype and phenotype segregation ratios for three possible scenarios are shown. S/s = ethanol-inducible cassette positive/negative, $\mathrm{A} / \mathrm{a}$ = wild-type $A B P 1 / a b p 1$ knock-out. Genotypes manifesting wild-type phenotype are shown on white background, KD phenotype on green background, genotypes that might exhibit both WT and KD phenotypes are on pale green background.

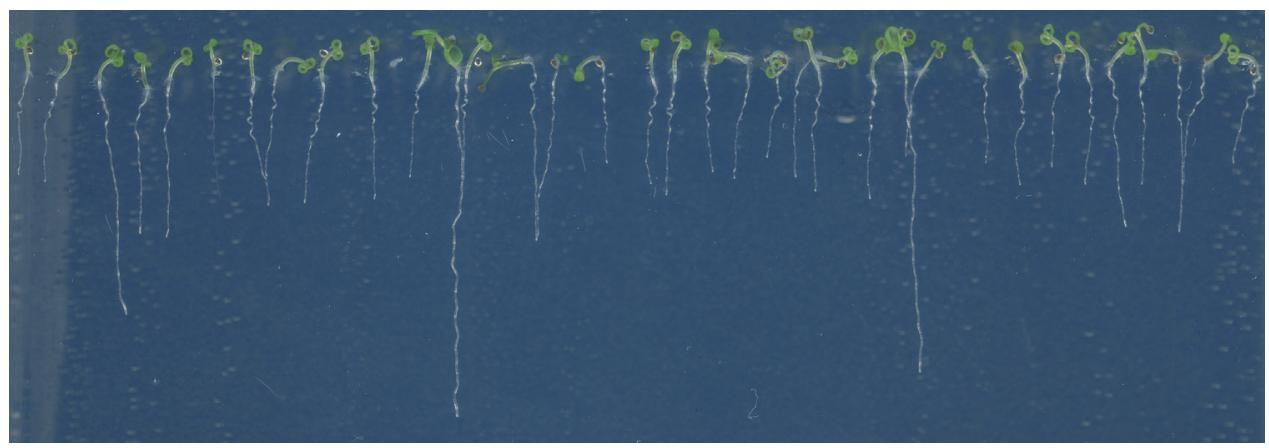

Supplementary Figure 2. Restoration of the ethanol-inducible phenotype in the progeny of the F2 WT-looking plant from the cross SS12K9 $\times$ abp1-c1 containing knock-down cassette and wild-type ABP1 version. In the presence of 5\% ethanol, F3 progeny show homogenous KD phenotype indicating that silencing of the construct might be responsible for wild-type phenotype of this plant in the F2 generation.

Barbier-Brygoo H, Ephritikhine G, Klämbt D, et al.: Functional evidence for an auxin receptor at the plasmalemma of tobacco mesophyll protoplasts. Proc Natl Acad Sci U S A. 1989; 86(3): 891-895.

PubMed Abstract | Publisher Full Text | Free Full Text

Batt S, Wilkins MB, Venis MA: Auxin binding to corn coleoptile membranes:

Kinetics and specificity. Planta. 1976; 130(1): 7-13.

PubMed Abstract | Publisher Full Text

Battaglia R, Brambilla V, Colombo L, et al.: Functional analysis of mads-box genes controlling ovule development in Arabidopsis using the ethanolinducible alc gene-expression system. Mech Dev. 2006; 123(4): 267-276. PubMed Abstract | Publisher Full Text

Braun N, Wyrzykowska J, Muller P, et al:: Conditional repression of AUXIN BINDING PROTEIN1 reveals that it coordinates cell division and cell expansion during postembryonic shoot development in Arabidopsis and tobacco. Plant Cell. 2008; 20(10): 2746-2762.

PubMed Abstract | Publisher Full Text | Free Full Text

Chen JG, Ullah H, Young JC, et al:: ABP1 is required for organized cell elongation and division in Arabidopsis embryogenesis. Genes Dev. 2001; 15(7): 902-911.

PubMed Abstract | Publisher Full Text | Free Full Text

Chen X, Grandont L, Li H, et al:: Inhibition of cell expansion by rapid ABP1mediated auxin effect on microtubules. Nature. 2014; 516(7529): 90-3. PubMed Abstract | Publisher Full Text | Free Full Text
Conrad U, Fiedler U: Compartment-specific accumulation of recombinant immunoglobulins in plant cells: an essential tool for antibody production and immunomodulation of physiological functions and pathogen activity. Plant Mol Biol. 1998; 38(1-2): 101-109.

PubMed Abstract | Publisher Full Text

Čovanová M, Sauer M, Rychtář J, et al.: Overexpression of the auxin binding protein1 modulates PIN-dependent auxin transport in tobacco cells. PLOS One. 2013; 8(7): e70050.

PubMed Abstract | Publisher Full Text | Free Full Text

Dai X, Zhang Y, Zhang D, et al:: Embryonic lethality of Arabidopsis abp1-1 is caused by deletion of the adjacent bsm gene. Nat Plants. 2015; 1: 15183. Publisher Full Text

David KM, Couch D, Braun N, et al.: The auxin-binding protein 1 is essential for the control of cell cycle. Plant J. 2007; 50(2): 197-206.

PubMed Abstract | Publisher Full Text

David KM, Perrot-Rechenmann C: Characterization of a tobacco Bright Yellow 2 cell line expressing the tetracycline repressor at a high level for strict regulation of transgene expression. Plant Physiol. 2001; 125(4): 1548-1553. PubMed Abstract | Publisher Full Text | Free Full Text

Deveaux Y, Peaucelle A, Roberts GR, et al.: The ethanol switch: a tool for tissue-specific gene induction during plant development. Plant J. 2003; 36(6): 918-930.

PubMed Abstract | Publisher Full Text 
Dhonukshe P, Aniento F, Hwang I, et al:: Clathrin-mediated constitutive endocytosis of PIN auxin efflux carriers in Arabidopsis. Curr Biol. 2007; 17(6): 520-527.

PubMed Abstract | Publisher Full Text

Dunwell JM, Purvis A, Khuri S: Cupins: the most functionally diverse protein superfamily? Phytochemistry. 2004; 65(1): 7-17.

PubMed Abstract | Publisher Full Text

Enders TA, Strader LC: Auxin activity: Past, present, and future. Am J Bot. 2015; 102(2): 180-196.

PubMed Abstract | Publisher Full Text

Gao $Y$, Zhang $Y$, Zhang D, et al.: Auxin binding protein 1 (ABP1) is not required for either auxin signaling or Arabidopsis development. Proc Natl Acad Sci U S A. 2015; 112(7): 2275-2280

PubMed Abstract | Publisher Full Text | Free Full Text

Grones P, Chen X, Simon S, et al.: Auxin-binding pocket of ABP1 is crucial for its gain-of-function cellular and developmental roles. J Exp Bot. 2015; 66(16): $5055-5065$.

PubMed Abstract | Publisher Full Text

Grones P, Friml J: Auxin transporters and binding proteins at a glance. J Cell Sci. 2015; 128(1): 1-7.

PubMed Abstract | Publisher Full Text

Grunewald W, Friml J: The march of the PINs: developmental plasticity by dynamic polar targeting in plant cells. EMBO J. 2010; 29(16): 2700-2714. PubMed Abstract | Publisher Full Text | Free Full Text

Habets ME, Offringa R: Auxin Binding Protein 1: A Red Herring After All? Mol Plant. 2015; 8(8): 1131-1134.

PubMed Abstract | Publisher Full Text

Hertel R, Thomson KS, Russo VE: In-vitro auxin binding to particulate cell

fractions from corn coleoptiles. Planta. 1972; 107(4): 325-340.

PubMed Abstract | Publisher Full Text

Laufs $\mathrm{P}$, Coen E, Kronenberger J, et al:: Separable roles of UFO during

floral development revealed by conditional restoration of gene function.

Development. 2003; 130(4): 785-796.

PubMed Abstract | Publisher Full Text

Leblanc N, David K, Grosclaude J, et al.: A novel immunological approach

establishes that the auxin-binding protein, Nt-abp1, is an element involved

in auxin signaling at the plasma membrane. J Biol Chem. 1999; 274(40):

$28314-28320$.

PubMed Abstract | Publisher Full Text

Livak KJ, Schmittgen TD: Analysis of relative gene expression data using real-

time quantitative PCR and the 2- $-\Delta c_{T}$ method. Methods. 2001; 25(4): 402-408.

PubMed Abstract | Publisher Full Text

Löbler M, Klämbt D: Auxin-binding protein from coleoptile membranes of corn (Zea mays L.). I. Purification by immunological methods and characterization. J Biol Chem. 1985; 260(17): 9848-9853.

PubMed Abstract

Maizel A, Weigel D: Temporally and spatially controlled induction of gene expression in Arabidopsis thaliana. Plant J. 2004; 38(1): 164-71.

PubMed Abstract | Publisher Full Text

Meister G, Tuschl T: Mechanisms of gene silencing by double-stranded RNA. Nature. 2004; 431(7006): 343-349.

PubMed Abstract | Publisher Full Text

Michalko J, Dravecká M, Bollenbach T, et al.: Embryo-lethal phenotypes in early abp1 mutants are due to disruption of the neighboring BSM gene [version 1; referees: 3 approved]. F1000Res. 2015; 4: 1104.

PubMed Abstract | Publisher Full Text | Free Full Text

Michalko J, Glanc M, Perrot-Rechenmann C, et al: Dataset 1 in: Strong morphological defects in conditional Arabidopsis abp1 knock-down mutants generated in absence of functional ABP1 protein. F1000Research. 2016a. Data Source

Michalko J, Glanc M, Perrot-Rechenmann C, et al:: Dataset 2 in: Strong morphological defects in conditional Arabidopsis abp1 knock-down mutants generated in absence of functional ABP1 protein. F1000Research. 2016b. Data Source

Michalko J, Glanc M, Perrot-Rechenmann C, et al:: Dataset 3 in: Strong morphological defects in conditional Arabidopsis abp1 knock-down mutants generated in absence of functional ABP1 protein. F1000Research. 2016c. Data Source
Nagawa S, Xu T, Lin D, et al.: ROP GTPase-dependent actin microfilaments promote PIN1 polarization by localized inhibition of clathrin-dependent endocytosis. PLOS Biol. 2012; 10(4): e1001299.

PubMed Abstract | Publisher Full Text | Free Full Text

Napier RM, David KM, Perrot-Rechenmann C: A short history of auxin-binding proteins. Plant Mol Biol. 2002; 49(3-4): 339-348.

PubMed Abstract | Publisher Full Text

Napier RM, Venis MA: Auxin action and auxin-binding proteins. New Phytol. 1995; 129(2): 167-201.

Publisher Full Text

Paciorek T, Zazímalová E, Ruthardt N, et al.: Auxin inhibits endocytosis and promotes its own efflux from cells. Nature. 2005; 435(7046): 1251-1256.

PubMed Abstract | Publisher Full Text

Paque S, Mouille G, Grandont L, et al:: AUXIN BINDING PROTEIN1 links cell wall remodeling, auxin signaling, and cell expansion in Arabidopsis. Plant Cell. 2014; 26(1): 280-295.

PubMed Abstract | Publisher Full Text | Free Full Text

Peaucelle A, Louvet R, Johansen JN, et al:: Arabidopsis phyllotaxis is controlled by the methyl-esterification status of cell-wall pectins. Curr Biol. 2008; 18(24): 1943-48. PubMed Abstract | Publisher Full Text

Petrásek J, Mravec J, Bouchard R, et al.: PIN proteins perform a rate-limiting function in cellular auxin efflux. Science. 2006; 312(5775): 914-918.

PubMed Abstract | Publisher Full Text

Pierre M, Traverso JA, Boisson B, et al.: $\mathbf{N}$-myristoylation regulates the SnRK1 pathway in Arabidopsis. Plant Cell. 2007; 19(9): 2804-2821.

PubMed Abstract | Publisher Full Text | Free Full Text

Ray PM, Dohrmann U, Hertel R: Characterization of naphthaleneacetic Acid binding to receptor sites on cellular membranes of maize coleoptile tissue. Plant Physiol. 1977; 59(3): 357-364.

PubMed Abstract | Publisher Full Text | Free Full Text

Robert S, Kleine-Vehn J, Barbez E, et al:: ABP1 mediates auxin inhibition of clathrin-dependent endocytosis in Arabidopsis. Cell. 2010; 143(1): 111-121. PubMed Abstract | Publisher Full Text | Free Full Text

Roslan HA, Salter MG, Wood CD, et al:: Characterization of the ethanolinducible alc gene-expression system in Arabidopsis thaliana. Plant J. 2001; 28(2): 225-35

PubMed Abstract | Publisher Full Text

Sassi M, Ali O, Boudon F, et al:: An auxin-mediated shift toward growth isotropy promotes organ formation at the shoot meristem in Arabidopsis. Curr Biol.

2014; 24(19): 2335-2342.

PubMed Abstract | Publisher Full Tex

Tromas A, Braun N, Muller $\mathrm{P}$, et al:: The AUXIN BINDING PROTEIN 1 is required for differential auxin responses mediating root growth. PLoS One. 2009; 4(9): e6648.

PubMed Abstract | Publisher Full Text | Free Full Text

Tromas A, Paponov I, Perrot-Rechenmann C: AUXIN BINDING PROTEIN 1: functional and evolutionary aspects. Trends Plant Sci. 2010; 15(8): 436-446. PubMed Abstract | Publisher Full Text

Tromas A, Paque S, Stierlé V, et al:: Auxin-binding protein 1 is a negative regulator of the SCFTR1/AFB pathway. Nat Commun. 2013; 4: 2496.

PubMed Abstract | Publisher Full Text

Tufarelli C, Stanley JA, Garrick D, et al.: Transcription of antisense RNA leading to gene silencing and methylation as a novel cause of human genetic disease. Nat Genet. 2003; 34(2): 157-165

PubMed Abstract | Publisher Full Tex

Tzafrir I, Pena-Muralla R, Dickerman A, et al:: Identification of genes required for embryo development in Arabidopsis. Plant Physiol. 2004; 135(3): 1206-1220. PubMed Abstract | Publisher Full Text | Free Full Text

Woo EJ, Marshall J, Bauly J, et al.: Crystal structure of auxin-binding protein 1 in complex with auxin. EMBO J. 2002; 21(12): 2877-2885.

PubMed Abstract | Publisher Full Text | Free Full Text

Xu T, Dai N, Chen J, et al.: Cell surface ABP1-TMK auxin-sensing complex activates ROP GTPase signaling. Science. 2014; 343(6174): 1025-1028. PubMed Abstract | Publisher Full Text | Free Full Text

Xu T, Wen M, Nagawa S, et al.: Cell surface- and rho GTPase-based auxin signaling controls cellular interdigitation in Arabidopsis. Cell. 2010; 143(1): 99-110.

PubMed Abstract | Publisher Full Text | Free Full Text 


\section{Open Peer Review}

\section{Current Peer Review Status: ? $\checkmark$}

\section{Version 1}

Reviewer Report 09 February 2016

https://doi.org/10.5256/f1000research.8243.r12003

(C) 2016 Luschnig C. This is an open access peer review report distributed under the terms of the Creative Commons Attribution License, which permits unrestricted use, distribution, and reproduction in any medium, provided the original work is properly cited.

\section{Christian Luschnig \\ Department of Applied Genetics and Cell Biology, University of Natural Resources and Life Sciences, Vienna, Austria}

In their $\mathrm{m} / \mathrm{s}$, the authors present an analysis of genetic interactions between published $A B P 1$ knockdown lines (based on antisense and immune-suppression approaches) and the Arabidopsis $A B P 1$ locus. After crossing three different knockdown lines into recently described abp1 knockout alleles, followed by segregation analysis of resulting F2 and F3 progeny, the authors came to the conclusion that growth defects of their knockdown lines do not depend on a functional $A B P 1$ locus.

These findings represent a valuable contribution to ongoing attempts, trying to clarify $A B P 1$ issues. Nevertheless, off-target loci recognized in the knockdown lines remain mysterious. Are there any ABP1-related loci (cupins?), expression of which could be affected by these knockdown lines? Perhaps this could be tested in the abp1-AS line.

Phenotypes of the knockdown lines are reminiscent of mutants with altered auxin responses. Did the authors look into expression of some of the characterized auxin-related loci? This could give us a better idea about the genetic determinants, causing the phenotypes in these knockdown lines.

Competing Interests: No competing interests were disclosed.

I confirm that I have read this submission and believe that I have an appropriate level of expertise to confirm that it is of an acceptable scientific standard, however I have significant reservations, as outlined above.

Reviewer Report 05 February 2016

https://doi.org/10.5256/f1000research.8243.r12004 
(C) 2016 Napier R. This is an open access peer review report distributed under the terms of the Creative Commons Attribution License, which permits unrestricted use, distribution, and reproduction in any medium, provided the original work is properly cited.

\section{Richard M. Napier}

School of Life Sciences, University of Warwick, Coventry, UK

The authors have produced a very thorough analysis of a set of well-known conditional ABP1 knock-down Arabidopsis lines. Using crosses with the recently-described abp1 knock-out lines from the work of Gao et al. (2015), the manuscript reveals that the phenotypes previously associated with loss of ABP1 can be induced even in genetic backgrounds that lack ABP1. These findings cover results from the two independent strategies used to create the conditional knockdown phenotypes, conditional immunosuppression and conditional antisense expression.

The assay used for this work was Arabidopsis root growth, not the very detailed phenotypes described recently from the conditional lines such as PIN endocytosis, ROP GTPase activation or microtubule rearrangement. However, impaired root growth was part of the initial suite of phenotypes associated with induced knock-down. The assays show very clearly that growth impairment correlates with the inheritance of the inducible cassette even in the absence of a functional ABP1 gene. We can surmise that the detailed subcellular phenotypes listed above are associated with the gross morphological changes recorded here. There is clearly some intriguing physiology associated with the switch induced by ethanol treatment, but ABP1 is not part of that story.

The title and abstract are appropriate (but see note below*), the work is done well, the data is presented clearly and fully, the text is very well structured and is easy to follow. There is a thorough introduction which explains how and why experimentation developed to tackle tangible problems linked to existing knowledge and understanding of ABP1 genetic resources. It is shown that the science was not misled by carelessness or device, that a spectrum of consistencies coloured the hypotheses covering ABP1 activity, and that these hypotheses have now been proven incorrect thanks to improved technologies, vigilance and critical reappraisal.

*The abstract ends with a sentence "...asks for further reflections on the biological function of ABP1 or alternative explanations for the missing phenotypic defects in the abp1 loss-of-function alleles." I think that this would be better if it read "... AND alternative explanations for the intriguing phenotypes previously associated with loss of ABP1 activity". Or similar. I understand that there is a requirement on all sides of the debate to be objective and critical about their data and no harm is done by registering this. However, the balance of probabilities needs to be recognised and, in my view, much more has to be gained from encouraging discovery of the root cause of the many fascinating phenotypes thrown up by the ABP1 KD lines than by searching absent defects. Therefore a small rewording at the end of the abstract is recommended. Otherwise I have no changes to suggest.

Competing Interests: No competing interests were disclosed.

I confirm that I have read this submission and believe that I have an appropriate level of 
expertise to confirm that it is of an acceptable scientific standard.

Reviewer Report 26 January 2016

https://doi.org/10.5256/f1000research.8243.r12006

(C) 2016 Ostergaard L. This is an open access peer review report distributed under the terms of the Creative Commons Attribution License, which permits unrestricted use, distribution, and reproduction in any medium, provided the original work is properly cited.

\section{Lars Ostergaard}

Department of Crop Genetics, John Innes Centre, Norwich, UK

In this manuscript, Michalko et al. investigates the basis of the developmental phenotypes observed in knock-down (KD) lines of the Arabidopsis ABP1 gene. By analysing segregation of defects in root elongation in the F2 and F3 generation of crosses between three KD abp1 alleles and two recently reported abp1 knock-out (KO) alleles, they conclude that the previously reported phenotypes of the KD lines are not due to loss of ABP1 function. The manuscript is clearly written and the experiments are thoroughly carried out providing an important contribution to the ABP1 saga.

Although I sympathise with the authors difficulty in identifying an explanation for how the KD lines can lead to the observed abnormalities, one experiment that should be done would in my opinion be a test of the expression of the closest $A B P 1$-like genes that can be identified.

Competing Interests: No competing interests were disclosed.

I confirm that I have read this submission and believe that I have an appropriate level of expertise to confirm that it is of an acceptable scientific standard, however I have significant reservations, as outlined above. 
The benefits of publishing with F1000Research:

- Your article is published within days, with no editorial bias

- You can publish traditional articles, null/negative results, case reports, data notes and more

- The peer review process is transparent and collaborative

- Your article is indexed in PubMed after passing peer review

- Dedicated customer support at every stage

For pre-submission enquiries, contact research@f1000.com 